\title{
Diastereochemical Differentiation of Some Cyclic and Bicyclic $\beta$-Amino Acids, Via the Kinetic Method
}

\author{
Anna R. M. Hyyryläinen, ${ }^{a}$ Jaana M. H. Pakarinen, ${ }^{a}$ Ferenc Fülöp, ${ }^{b}$ \\ and Pirjo Vainiotalo ${ }^{\mathrm{a}}$ \\ a Department of Chemistry, University of Joensuu, Joensuu, Finland \\ ${ }^{b}$ Institute of Pharmaceutical Chemistry, University of Szeged, Szeged, Hungary
}

Stereochemical differentiation of five diastereomeric pairs of $\beta$-amino acids, di-endo- and di-exo-2,3disubstituted norbornane and norbornene amino acids, cis- and trans-2-aminocyclohexane-, 2-amino-4-cyclohexene-, and 2-aminocyclopentanecarboxylic acids, was investigated via the kinetic method with metal-bound trimeric complexes. This is the first time that diastereomers (di-endo/di-exo and cis/trans) have been differentiated with metal-bound trimeric complexes and the kinetic method. Moreover, determination of diastereochemical excess by the kinetic method was applied to norbornane $\beta$-amino acids and cyclopentane $\beta$-amino acids. Experiments showed that a remarkable differentiation of the studied diastereomers was achieved. It was observed that better selectivity values correlated to more rigid structures. The reference compounds for the studied $\beta$-amino acids varied from $\alpha$-amino acids to some $\beta$-amino acids. In addition, variation of the metal ion $\left(\mathrm{Cu}^{2+}\right.$ and $\left.\mathrm{Ni}^{2+}\right)$ had some role in the selectivity values obtained. Ab initio and hybrid density functional theory calculations were performed to clarify the results obtained by mass spectrometry. (J Am Soc Mass Spectrom 2009, 20, 34-41) (C) 2009 Published by Elsevier Inc. on behalf of American Society for Mass Spectrometry

$\mathrm{T}$ The kinetic method, introduced by R. Graham Cooks, is a technique used for the determination of thermochemical values such as proton affinity, ionization energy, and gas-phase basicity [1-3]. Another application of the kinetic method has been the differentiation of isomers, mainly enantiomers [4-6].

In the field of chiral analysis, Cooks and coworkers showed that dissociation kinetics of transition-metal ion trimeric complexes can be used to differentiate enantiomers of $\alpha$-amino acids [6-8]. Later on, differentiation of enantiomers using the kinetic method received a lot of interest, thus different kinds of enantiomers have been separated [9-20]. In this method, singly charged trimeric metal-bound complexes are formed and the ion of interest, a trimeric metal bound complex $\left[\mathrm{M}^{2+}\left(\operatorname{ref}^{*}\right)_{2}(\mathrm{~A})-\mathrm{H}\right]^{+}$, is isolated. These trimeric complex ions are then dissociated to form dimeric complexes via collision-induced dissociation (CID),

$$
\begin{aligned}
& \mathrm{A} \underset{\mathrm{ESI}}{\stackrel{\mathrm{M}^{2+}, \mathrm{ref}^{*}}{\longrightarrow}}\left[\mathrm{M}^{2+}\left(\mathrm{ref}^{*}\right)_{2}(\mathrm{~A})-\mathrm{H}\right]^{+} \\
& \longrightarrow\left[\mathrm{M}^{2+}\left(\mathrm{ref}^{*}\right)(\mathrm{A})-\mathrm{H}\right]^{+} \mathrm{ref}^{*} \\
& \longrightarrow\left[\mathrm{M}^{2+}\left(\mathrm{ref}^{*}\right)_{2}-\mathrm{H}\right]^{+}+\mathrm{A}
\end{aligned}
$$

Address reprint requests to Professor Pirjo Vainiotalo, Department of Chemistry, University of Joensuu, P.O. Box 111, FI-80101 Joensuu, Finland. E-mail: pirjo.vainiotalo@joensuu.fi where $\mathrm{A}$ is an analyte of interest, $\mathrm{M}^{2+}$ is a divalent metal ion, and ref* is a chiral reference compound. The abundance ratios of these $\left[\mathrm{M}^{2+}\left(\mathrm{ref}^{*}\right)(\mathrm{A})-\mathrm{H}\right]^{+}$and $\left[\mathrm{M}^{2+}\left(\operatorname{ref}^{*}\right)_{2}-\mathrm{H}\right]^{+}$fragment ions strongly depend on the stereochemistry of the ligands in the trimeric complex $\left[\mathrm{M}^{2+}\left(\operatorname{ref}^{*}\right)_{2}(\mathrm{~A})-\mathrm{H}\right]^{+}$ion. The electronic and steric effects of the chiral reference compound have major roles in achieving the selectivity. Together with the reference molecule, the metal ion plays a large role in achieving the differentiation of isomers. Because different transition-metal ions have different electronic configurations, they also have different stereochemical effects [9]. In this method, a chiral selectivity $\left(\mathrm{R}_{\text {chiral }}\right)$ is defined as the ratio of $R_{R} / R_{S}$, where $R_{R}$ or $R_{S}$ is defined as:

$$
\mathrm{R}_{\mathrm{R}} \text { or } \mathrm{R}_{\mathrm{S}}=\left[\mathrm{M}^{2+}\left(\text { ref }^{*}\right)\left(\mathrm{A}_{\mathrm{R}} \text { or } \mathrm{A}_{\mathrm{S}}\right)-\mathrm{H}\right]^{+} /\left[\mathrm{M}^{2+}\left(\text { ref }^{*}\right)_{2}-\mathrm{H}\right]^{+}
$$

In this study, the applicability of the kinetic method and trimeric complexes was tested for its ability to differentiate diastereomeric $\beta$-amino acids (both diendo/di-exo and cis/trans isomers). The diastereoselectivity $\left(R_{d}\right)$ is defined as the ratio of $R_{\text {diendo }} / R_{\text {diexo }}$ (respectively $\left.R_{\text {cis }} / R_{\text {trans }}\right)$. As in the case of chiral analysis, the larger the difference between $R_{d}$ and unity (1) the higher the degree of diastereoselectivity.

Stereochemical differentiation by the kinetic method was performed for both bicyclic (1-4) and cyclic
(C) 2009 Published by Elsevier Inc. on behalf of American Society for Mass Spectrometry. 1044-0305/09/\$32.00

doi:10.1016/j.jasms.2008.09.018
Published online September 25, 2008 Received August 5, 2008 Revised September 12, 2008 Accepted September 13, 2008 


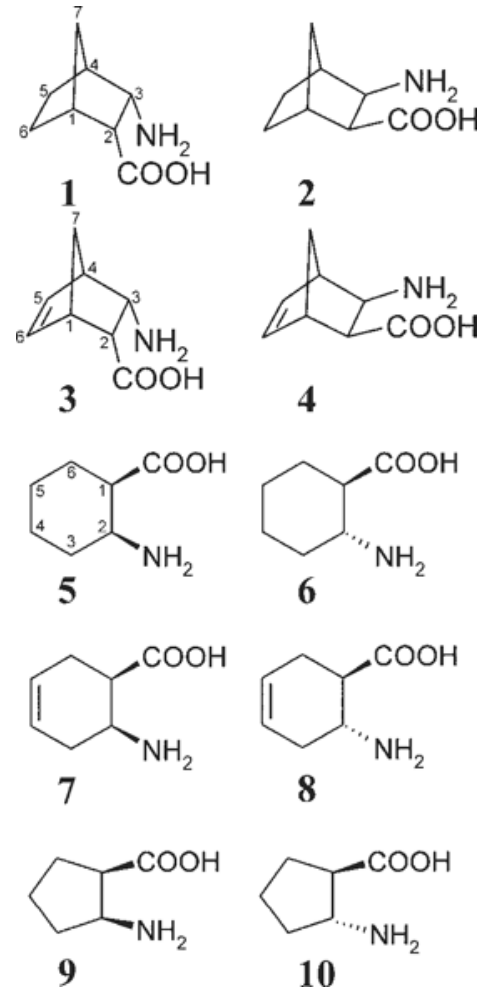

Scheme 1. Di-endo- and di-exo-isomers of the bicyclic $\beta$-amino acids (1-4), and cis- and trans-isomers of the cyclic $\beta$-amino acids (5-10) studied.

$\beta$-amino acids (5-10) (Scheme 1). Among the cyclic $\beta$-amino acids, the most widely investigated are the five- and six-member compounds, for example $(1 R, 2 S)$ 2-aminocyclopentanecarboxylic acid (cispentacin), an antifungal antibiotic which has been isolated from $B a$ cillus cereus and Streptomyces setonii [21]. In addition, cyclic $\beta$-amino acids are mentioned as building blocks for the preparation of modified analogues of biologically active peptides, as starting substances for different heterocycles, as potential pharmacons, and as building blocks in drug research [21, 22].

The differentiation of some of these studied diastereomeric $\beta$-amino acids has been evaluated before with chemical and electron ionization, but differentiation of isomers has proved to be challenging [23]. In our earlier study, we differentiated these $\beta$-amino acids through ion/molecule reactions $[24,25]$. Especially for the studied cyclic $\beta$-amino acids, moderate selectivities were achieved by using host-guest complexes and ion/ molecule reactions. So, in view of achieving better differentiation, the kinetic method was applied. This method proved interesting because it offered wide opportunities to alternate reference compounds, as well as metal ions. Different reference compounds for the different $\beta$-amino acids studied varied from $\alpha$-amino acids [D-proline (D-Pro), L-proline (L-Pro), and Lphenylalanine (L-Phe)] to some $\beta$-amino acids. The $\beta$-amino acids used as reference compounds were diexo norbornane $\beta$-amino acid (2), cis-cyclohexane $\beta$-amino acid (5), cis- and trans-cyclohexene $\beta$-amino acid (7 and 8$)$, and $(1 S, 2 R)$-cycloheptane $\beta$-amino acid. In addition, we tried to use other reference compounds, but a trimeric metal-bound complex was not observed in some cases, or the abundance of the ion of interest was too low for isolation, and thus for dissociation. In this study, both $\mathrm{Cu}^{2+}$ and $\mathrm{Ni}^{2+}$ were used as the central metal ions for all diastereoisomeric $\beta$-amino acids (110). Apart from the diastereomeric differentiation of the studied $\beta$-amino acids, determination of diastereomeric excess was also performed for the norbornane (1 and 2 ) and cyclopentane (9 and 10) $\beta$-amino acids.

\section{Experimental}

For the kinetic method experiments, the trimeric metalbound complexes were generated by mixing a 1:1 solution of methanol-water that contained a stereoisomer of interest and a reference compound, at a concentration of $50 \mu \mathrm{M}$ each, and $10 \mu \mathrm{M}$ transition-metal salt. In some experiments, a higher concentration of metal salt $(50 \mu \mathrm{M})$ was needed due to a low abundance of the trimeric complex. Variation of the metal concentration, however, did not contribute to the selectivity values obtained.

Cupric chloride $\left(\mathrm{CuCl}_{2} \cdot 2 \mathrm{H}_{2} \mathrm{O}\right)$ and nickel nitrate $\left(\mathrm{Ni}\left(\mathrm{NO}_{3}\right)_{2} \cdot 6 \mathrm{H}_{2} \mathrm{O}\right)$, obtained from Merck (Darmstadt, Germany), were used as sources of metal ions. Reference compounds, L-phenylalanine and L-proline, were obtained from Sigma (St. Louis, USA), and D-proline was obtained from Aldrich-Chemie (Steinheim, Germany). Other compounds used as references, di-exo-2,3-disubstituted norbornane amino acid (2), cis-2-aminocyclohexanecarboxylic acid (5), cis- and trans-2-aminocyclohexenecarboxylic acid (7 and 8), and $(1 S, 2 R)$-2-aminocycloheptanecarboxylic acid, were obtained from the Institute of Pharmaceutical Chemistry, University of Szeged, Szeged, Hungary.

The kinetic method mass spectrometry experiments were performed with a quadrupole ion trap (QIT) mass spectrometer (Bruker Esquire 3000 plus; Bruker Daltonik $\mathrm{GmbH}$, Bremen, Germany) with an external ESI source. A pressure of $10^{-6}$ to $10^{-5}$ mbar was maintained by rotary vacuum and turbomolecular pumps supplied by Edwards (Edwards High Vacuum International, Crawley, UK). The sample was introduced to the mass spectrometer via an orthogonal sprayer at a rate of 120 $\mu \mathrm{L} / \mathrm{h}$. Nitrogen, heated at $250{ }^{\circ} \mathrm{C}$, was used as a nebulization and drying gas, and helium as a buffer/collision gas. The parameters of the ion source were optimized, so that the intensity of the precursor ion and the stability of the signal were optimal. Identical conditions were created for diastereomer pairs, and the conditions for different kinds of trimeric complexes, including variation of the metal and reference compound, were kept as similar as possible. For all the measurements, the ion charge control target was 20,000 and the maximum allowed acquisition time was $50 \mathrm{~ms}$. The trap drive value was 45 . Each spectrum was an average of 7 to 10 spectra collected within $1 \mathrm{~min}$, each of them 
containing 30 individual scans, which were averaged. The measurements and data handling were performed with a Bruker Daltonics Compass 1.1 for Esquire/HCT. The results obtained were calculated as average values from three measurements, except in the case of the determination of diastereomeric excess, where five measurements were conducted for the "unknown" samples. The errors shown in this paper are presented as a standard deviation.

In the CID experiments, both the precursor ion isolation and the fragmentation widths were $3.0 \mathrm{~m} / \mathrm{z}$. The length of the fragmentation pulse was $6 \mathrm{~ms}$ and the low mass cut-off was $27 \%$. The fragmentation amplitudes varied from 0.20 to $0.55 \mathrm{~V}$, depending on the complexes, but the same fragmentation amplitude values were used for each diastereomeric pair.

\section{Theoretical Calculations}

$\mathrm{Ab}$ initio and hybrid density functional theory (DFT) calculations were performed with the Gaussian03 [26] series of programs on Intel Pentium 4 Xeon hardware at the University of Joensuu. First, the structures of the dimeric complexes were optimized with a restricted Hartree-Fock (RHF) procedure and the 3-21G basis set. The final optimization for the most stable structures of the dimeric complexes with norbornane ( $\mathbf{1}$ and 2 ) and norbornene (3 and 4) $\beta$-amino acid structures and harmonic frequency analysis was done with the B3LYP/6-31G $(d, p)$ basis set. For both the basis sets, a LANL2DZ basis set was used for the $\mathrm{Cu}^{2+}$ and $\mathrm{Ni}^{2+}$ and only outer core electrons were considered, because they are mainly responsible for bonding interactions [27]. Since no imaginary frequencies were obtained, the structures correspond to the true equilibrium configuration. Structures were visualized with GaussView 3.0 [28].

\section{Results and Discussion}

Because the metal ion affinities of studied $\beta$-amino acids (1-10) have not been determined, the selection of suitable reference compounds was challenging. First, we started with some $\beta$-amino acids, but some $\alpha$-amino acids were also selected. Divalent copper and nickel were selected as the central metal ions due to their wide use in the field of chiral differentiation of $\alpha$-amino acids and other small organic molecules [6-10]. It is important to note that if the difference between the metal ion affinities of the analyte and the reference compound is too large, dissociation of the isolated trimeric complex ions favors only one fragmentation path. In some cases, in this study, the trimeric complexes mainly dissociated by forming one fragment ion, but the abundance of the other fragment ion was adequate for calculations. This was especially the case with cyclohexane $\beta$-amino acids (5 and $\mathbf{6}$ ), when L-Phe was used as a reference compound.
Dissociation of trimeric $\left[\mathrm{M}^{2+}(\mathrm{ref})_{2} \mathrm{~A}-\mathrm{H}\right]^{+}$complex ions containing $\mathrm{Cu}^{2+}$ or $\mathrm{Ni}^{2+}$ metal ions, a reference compound (ref), and a diastereomer of interest, mainly led to the formation of two competitive dimeric fragment ions $\left[\mathrm{M}^{2+} \text { (ref) } \mathrm{A}-\mathrm{H}\right]^{+}$and $\left[\mathrm{M}^{2+}(\text { ref })_{2}-\mathrm{H}\right]^{+}$. In some cases, when $\mathrm{Cu}^{2+}$ was used as a metal ion, CID spectra showed additional fragment ions [29, 30]. The additional fragment ions derived from two dimeric fragment ions as a consequence of a loss of $\mathrm{CO}_{2}$, mainly from the $\left[\mathrm{Cu}^{2+} \text { (ref)A }-\mathrm{H}\right]^{+}$complex ion. The abundances of the additional fragment ions were not high, but the selectivity values were calculated by including all fragment ions, and $\mathrm{MS}^{3}$ measurements were performed to ensure that additional fragmentation was derived from the dissociation of dimeric complexes. When $\mathrm{Ni}^{2+}$ was used as a metal ion, this additional fragmentation was not observed.

In the case of bicyclic norbornane $\beta$-amino acids (1 and 2), notable differentiation was achieved with the kinetic method that uses different metal ions and reference compounds. Table 1 presents the diastereoselectivity values $\left(\mathrm{R}_{\text {diendo/diexo }}\right)$ obtained for $\mathbf{1}$ and 2 . In general, better selectivity values were obtained with prolines than with a cis-cyclohexane $\beta$-amino acid (5) as a reference compound. This is a little bit surprising because the structure of cyclohexane $\beta$-amino acid (5) is more similar to the studied norbornane $\beta$-amino acid than proline, which is an $\alpha$-amino acid. In addition, altering the metal ion had some influence on the selectivity values observed. $\mathrm{Ni}^{2+}$ as a metal ion gave better selectivity values than $\mathrm{Cu}^{2+}$, and in the case of $\mathrm{Cu}^{2+}$ some additional fragmentation was observed. The highest selectivity value was achieved by using $\mathrm{Ni}^{2+}$ as a metal ion and L-proline as a reference compound. Moreover, di-endo and di-exo norbornene $\beta$-amino acids (3 and 4) were tried as reference compounds, with both $\mathrm{Cu}^{2+}$ and $\mathrm{Ni}^{2+}$ as a metal ion, but the abundances of all these trimeric complex ions were too low or unstable for the isolation (data not shown here).

Figure 1 presents the CID spectra of di-endo and di-exo isomers of norbornane $\beta$-amino acid ( $\mathbf{1}$ and 2 ) when $\mathrm{Ni}^{2+}$ was used as a metal ion and D-Pro as a reference compound. The protonated isomer was observed in some cases in CID spectra, but it was ignored.

It is worth noting that all the selectivity values obtained were below one, indicating that a di-endo

Table 1. Diastereoselectivities for bicyclic norbornane $\beta$-amino acids (1 and 2) with different metal ions and reference compounds

\begin{tabular}{lcc}
\hline Metal ion & Reference & $\begin{array}{c}\text { Diastereoselectivity } \\
\left(R_{\text {diendo/diexo }}\right)\end{array}$ \\
\hline \hline $\mathrm{Cu}^{2+}$ & L-Pro* & $0.023 \pm 0.005$ \\
$\mathrm{Cu}^{2+}$ & D-Pro* & $0.021 \pm 0.003$ \\
$\mathrm{Cu}^{2+}$ & $\mathbf{5}$ & $0.040 \pm 0.003$ \\
$\mathrm{Ni}^{2+}$ & L-Pro & $0.006 \pm 0.001$ \\
$\mathrm{Ni}^{2+}$ & D-Pro & $0.008 \pm 0.001$ \\
$\mathrm{Ni}^{2+}$ & $\mathbf{5}$ & $0.015 \pm 0.003$ \\
\hline
\end{tabular}

*More fragments were observed. 
isomer forms weaker bonds with a metal ion compared with a di-exo isomer. With a di-endo isomer, the abundance of the $\left[\mathrm{M}^{2+}(\mathrm{ref})_{2}-\mathrm{H}\right]^{+}$complex ion was much higher than the other main fragment ion. The reason for this kind of behavior was evaluated through theoretical calculations. As can be seen in Figure 2, the lowest energy structures of di-endo and di-exo dimeric complex ions notably differ from each other. In the case of the di-endo isomer (Figure 2a), the adjacent endo-hydrogens in the fifth and sixth carbons are quite near to the amino and carboxyl group, thus generating some steric hindrance and repulsive forces, which might weaken the complexation with metal. With the di-exo isomer (Figure $2 b$ ), the structure is more open, thus allowing easier complexation with the metal. DFT calculations also revealed that a complex with a di-exo isomer (Figure $2 b$ ) is more stable than a complex with a di-endo isomer.

It was also noted in our earlier study that these diastereomeric norbornane $\beta$-amino acids were easily differentiated by using host-guest complexes and ion/ molecule reactions [24]. With this method, isomers were differentiated with tetraethyl resorcarene as a host molecule and $n$-propylamine as a neutral reagent. The

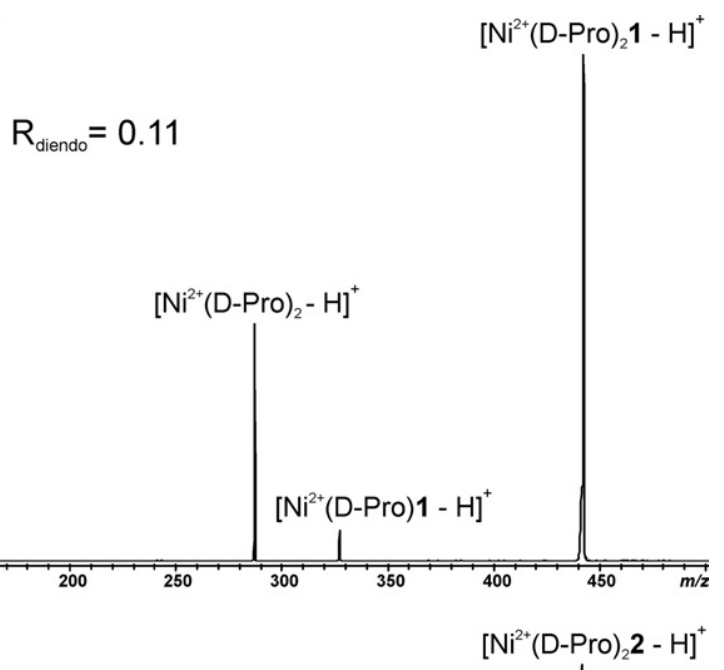

$$
\begin{aligned}
& R_{\text {diexo }}=14.4 \\
& R_{\text {diendo/liexo }}=0.008 \pm 0.001
\end{aligned}
$$

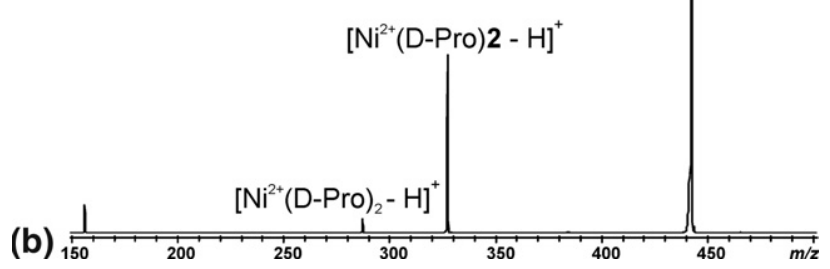

Figure 1. CID spectra of trimeric complexes. (a) Di-endo and (b) di-exo isomers of norbornane $\beta$-amino acid $(\mathbf{1}$ and 2$) . \mathrm{Ni}^{2+}$ was used as a metal ion and D-Pro as a reference compound. The fragmentation amplitude was $0.22 \mathrm{~V}$.

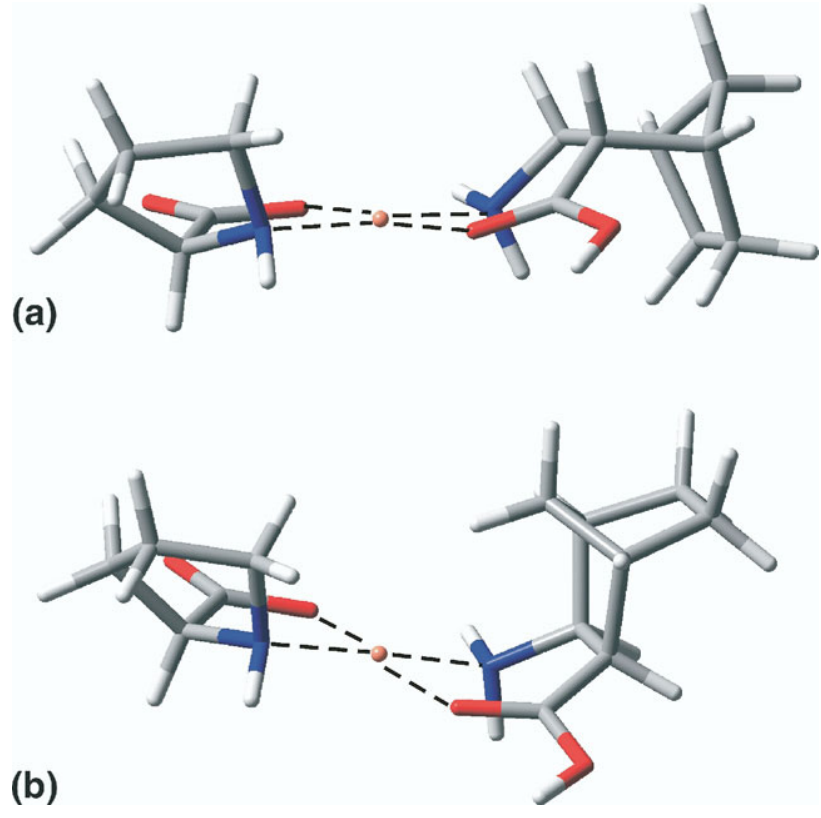

Figure 2. The lowest energy B3LYP/6-31G $(\mathrm{d}, \mathrm{p})[\mathrm{C}, \mathrm{N}, \mathrm{O}, \mathrm{H}]$ and LANL2DZ[Cu] structures for the dimeric complexes (a) di-endo and (b) di-exo-norbornane $\beta$-amino acids ( $\mathbf{1}$ and $\mathbf{2}) . \mathrm{Cu}^{2+}$ was used as a metal ion and L-Pro as a reference compound.

diastereoselectivity appeared in different reaction rates by the isomers in the gas-phase reactions. With a di-endo isomer (1), the guest-exchange reactions were much faster than with a di-exo isomer (2), thus, the selectivity value was as high as 13 .

In the case of norbornene $\beta$-amino acids ( 3 and 4 ), diastereochemical differentiation was also achieved (Table 2). Again, good selectivities were achieved by using prolines as reference compounds, but in this case the similarity of the analyte compound and the reference compound [di-exo-norbornane $\beta$-amino acid (2)] yielded significant diastereoselectivity. In addition to the reference compounds shown in Table 2, several other compounds were investigated, but the dissociation of trimeric complexes mainly showed only one fragmentation path, thus, it was not possible to calculate the selectivity values.

Again, measurements were conducted by using both $\mathrm{Cu}^{2+}$ and $\mathrm{Ni}^{2+}$ as metal ions. Some additional fragmen-

Table 2. Diastereoselectivities for bicyclic norbornene $\beta$-amino acids (3 and 4 ) with different metal ions and reference compounds

\begin{tabular}{lcc}
\hline Metal ion & Reference & $\begin{array}{c}\text { Diastereoselectivity } \\
\left(R_{\text {diendo/diexo }}\right)\end{array}$ \\
\hline \hline $\mathrm{Cu}^{2+}$ & L-Pro* & $15.16 \pm 1.44$ \\
$\mathrm{Cu}^{2+}$ & D-Pro* & $19.83 \pm 0.51$ \\
$\mathrm{Cu}^{2+}$ & $2^{*}$ & $19.44 \pm 3.00$ \\
$\mathrm{Ni}^{2+}$ & L-Pro & $5.20 \pm 1.63$ \\
$\mathrm{Ni}^{2+}$ & D-Pro & $5.75 \pm 0.37$ \\
$\mathrm{Ni}^{2+}$ & $\mathbf{2}$ & $12.72 \pm 1.88$ \\
\hline
\end{tabular}

*More fragments were observed. 
(a)

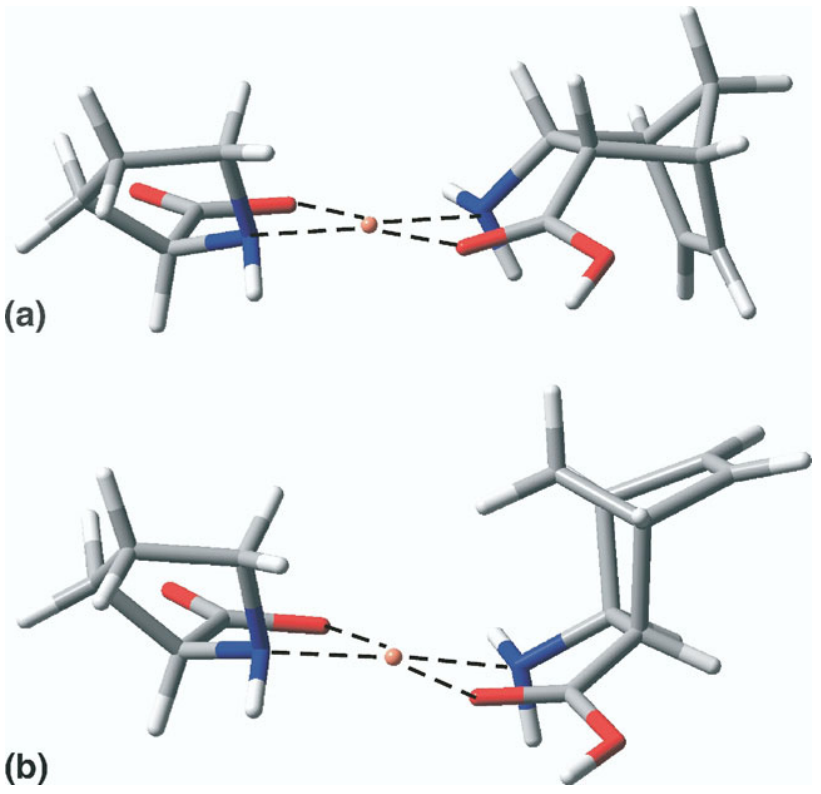

Figure 3. Lowest energy B3LYP/6-31G $(\mathrm{d}, \mathrm{p})[\mathrm{C}, \mathrm{N}, \mathrm{O}, \mathrm{H}]$ and LANL2DZ[Cu] structures for the dimeric complexes (a) di-endo and (b) di-exo-norbornene $\beta$-amino acids ( 3 and 4 ). $\mathrm{Cu}^{2+}$ was used as a metal ion and L-Pro as a reference compound.

tation was observed in all the cases where $\mathrm{Cu}^{2+}$ was used as a metal ion. In the L- and D-proline cases, the additional fragmentation was due to the loss of $\mathrm{CO}_{2}$ mainly from $\left[\mathrm{Cu}^{2+}(\text { Pro }) 3-\mathrm{H}\right]^{+\bullet}$ and $\left[\mathrm{Cu}^{2+}(\right.$ Pro $) 4-$ $\mathrm{H}]^{+\bullet}$ complex ions. When a di-exo norbornane $\beta$-amino acid (2) was used as a reference compound, additional fragmentation was derived from the loss of $66 \mathrm{Da}$ (cyclopentadiene, $\mathrm{C}_{5} \mathrm{H}_{6}$ ) of the dimeric complex ion, which could indicate a retro Diels-Alder reaction. This kind of fragmentation indicates that copper forms very strong bonds with the analyte because the breaking of the carbon bond is preferred over the metal bond. With $\mathrm{Ni}^{2+}$, clean CID spectra were obtained without additional fragmentation, thus the emphasis is on the selectivity values obtained with $\mathrm{Ni}^{2+}$. The highest selectivity value for $\mathrm{Ni}^{2+}$ was achieved with a di-exo norbornane $\beta$-amino acid (2) as a reference compound.

Now, all diastereoselectivity values obtained are above one. The reason for this kind of behavior can be explained by exploring the structures of dimeric complex ions (Figure 3). A dimeric complex ion with a di-endo isomer (3) (Figure 3a) is more open to the formation of a metal bond than a di-exo isomer (4), thus a di-endo isomer forms stronger interactions with metal. In addition, the adjacent hydrogens in the fifth and sixth carbons are located further away than in the case of di-endo norbornane $\beta$-amino acid (1), so the repulsive effect is minor. According to the DFT calculations, a dimeric ion with a di-endo isomer is energetically more stable, so once again our theoretical calculations were in good agreement with the results obtained by mass spectrometry.

Moreover, we have previously differentiated these studied $\beta$-amino acids with host-guest complexes and ion/molecule reactions [24], but better results (higher selectivity values) were now achieved through the kinetic method.

Differentiation of cyclic $\beta$-amino acids (5-10) was successful, as well. Good selectivity values were achieved with both $\mathrm{Cu}^{2+}$ and $\mathrm{Ni}^{2+}$ as metal ions, and with different reference compounds. In general, the selectivity values were lower than in the case of bicyclic $\beta$-amino acids, but notable selectivity was still obtained. The diastereoselectivities $\left(\mathrm{R}_{c i s / \text { trans }}\right)$ for cyclohexane $\beta$-amino acids (5 and $\mathbf{6}$ ) are presented in Table 3.

Different reference compounds were tried for the cyclohexane $\beta$-amino acids (5 and 6 ) to enhance the obtained selectivity values. Thus, some $\alpha$ - and $\beta$-amino acids were both tried as reference compounds. It was once again observed that the highest selectivity values were achieved with prolines. The similarity between the analyte ( 5 and 6 ) and the reference compound ( 7 and 8 ) did not improve the selectivity value. Moreover, it was noticed that altering a metal ion did not greatly influence the results obtained. Again, some additional fragmentation was observed when $\mathrm{Cu}^{2+}$ was used as a metal ion. This additional fragmentation (the loss of $\mathrm{CO}_{2}$ from the dimeric complex ion) was observed even if the reference compound was changed. When $\mathrm{Ni}^{2+}$ was used as a metal ion, nice clean CID spectra were achieved, regardless of whether the reference compounds were altered, so once again the emphasis is on the results obtained with $\mathrm{Ni}^{2+}$.

Although these selectivity values are not as significant as in the case of bicyclic $\beta$-amino acids, they are a little bit higher than those values obtained in our earlier study that used host-guest complexes and ion/molecule reactions [25].

Table 4 presents corresponding selectivity values for cyclohexene $\beta$-amino acids ( 7 and 8 ). Once again, different kinds of reference compounds were used. As in the case of cyclohexane $\beta$-amino acids ( 5 and 6 ), prolines used as reference compounds yielded the highest selectivity value, and the similarity of the analyte and the reference compound (5) did not improve the selectivity values. Yet, some difference was observed between the selectivity values when $\mathrm{Cu}^{2+}$ or $\mathrm{Ni}^{2+}$ was

Table 3. Diastereoselectivities for cyclohexane $\beta$-amino acids (5 and 6) with different metal ions and reference compounds

\begin{tabular}{lcc}
\hline Metal ion & Reference & $\begin{array}{c}\text { Diastereoselectivity } \\
\left(\mathrm{R}_{\text {cis/trans }}\right)\end{array}$ \\
\hline \hline $\mathrm{Cu}^{2+}$ & L-Pro* & $2.89 \pm 0.13$ \\
$\mathrm{Cu}^{2+}$ & D-Pro* & $2.78 \pm 0.24$ \\
$\mathrm{Cu}^{2+}$ & L-Phe* & $1.94 \pm 0.35$ \\
$\mathrm{Cu}^{2+}$ & $\mathbf{1 1 * *}$ & $1.82 \pm 0.03$ \\
$\mathrm{Ni}^{2+}$ & L-Pro & $2.10 \pm 0.37$ \\
$\mathrm{Ni}^{2+}$ & D-Pro & $2.38 \pm 0.10$ \\
$\mathrm{Ni}^{2+}$ & $\mathbf{7}$ & $1.67 \pm 0.16$ \\
$\mathrm{Ni}^{2+}$ & $\mathbf{8}$ & $1.52 \pm 0.17$ \\
$\mathrm{Ni}^{2+}$ & $\mathbf{1 1 * *}$ & $1.48 \pm 0.05$ \\
\hline
\end{tabular}

* More fragments were observed.

**11 is $(1 S, 2 R)-2$-aminocycloheptanecarboxylic acid. 
used as a metal ion. It seems that $\mathrm{Cu}^{2+}$ with $\mathrm{L}^{-}$or D-proline forms a highly suitable environment for the differentiation of diastereomeric cyclohexene $\beta$-amino acids. The selectivity values are around 10 but some additional fragmentation (the loss of $\mathrm{CO}_{2}$ ) was observed with $\mathrm{Cu}^{2+}$. However, high diastereoselectivity without additional fragmentation was achieved when $\mathrm{Ni}^{2+}$ was used as a metal ion and prolines as reference compounds.

The selectivity values of cyclohexene $\beta$-amino acids (7 and 8) are higher than with cyclohexane $\beta$-amino acids (5 and 6). The double bond in the cyclohexane skeleton stiffens the structure of the $\beta$-amino acid; thus the differentiation of cyclohexene $\beta$-amino acid is more favorable. In our previous study, only moderate selectivities were achieved for the cyclohexene $\beta$-amino acids when we used ion/molecule reactions and hostguest complexes [25].

Different reference compounds and metal ions were also used in the case of cyclopentane $\beta$-amino acids (9 and 10). Table 5 presents selectivity values for cyclopentane $\beta$-amino acids. Reference compounds varied from prolines to cis-cyclohexane $\beta$-amino acid (5). Dand L-Pro as reference compounds gave good selectivity values, as did cis-cyclohexane $\beta$-amino acid (5) with $\mathrm{Ni}^{2+}$. Overall, slightly better selectivity values were obtained when $\mathrm{Ni}^{2+}$ was used as a metal ion. One interesting thing was that now additional fragmentation (the loss of $\mathrm{CO}_{2}$ ) was not observed for the $\mathrm{Cu}^{2+}$ complexes.

In our earlier study, differentiation of diastereomeric cyclopentane $\beta$-amino acids through ion/molecule reactions gave only moderate selectivity values [25]. However, in this study, good selectivities were achieved. It was interesting to note that with the kinetic method better selectivity values were obtained for more rigid cyclopentane $\beta$-amino acids (9 and 10) (Table 5) than for cyclohexane $\beta$-amino acids (5 and 6) (Table 3). In the case of ion/molecule reactions, the situation was reversed [25].

As an example, Figure 4 presents the CID spectra of cis- and trans-isomers of cyclopentane $\beta$-amino acid (9 and 10). One can see that both spectra are very clean:

Table 4. Diastereoselectivities for cyclohexene $\beta$-amino acids (7 and 8 ) with different metal ions and reference compounds

\begin{tabular}{lcc}
\hline Metal ion & Reference & $\begin{array}{c}\text { Diastereoselectivity } \\
\left(\mathrm{R}_{\text {cis/trans }}\right)\end{array}$ \\
\hline \hline $\mathrm{Cu}^{2+}$ & L-Pro* & $9.89 \pm 0.17$ \\
$\mathrm{Cu}^{2+}$ & D-Pro* & $10.43 \pm 0.25$ \\
$\mathrm{Cu}^{2+}$ & L-Phe* & $6.87 \pm 1.47$ \\
$\mathrm{Cu}^{2+}$ & $\mathbf{1 1}{ }^{* *}$ & $3.05 \pm 0.36$ \\
$\mathrm{Cu}^{2+}$ & $\mathbf{5}$ & $3.10 \pm 0.09$ \\
$\mathrm{Ni}^{2+}$ & L-Pro & $6.15 \pm 0.86$ \\
$\mathrm{Ni}^{2+}$ & D-Pro & $7.64 \pm 0.31$ \\
$\mathrm{Ni}^{2+}$ & $\mathbf{1 1}$ & $3.08 \pm 0.27$ \\
$\mathrm{Ni}^{2+}$ & $\mathbf{5}$ & $2.93 \pm 0.21$ \\
\hline
\end{tabular}

* More fragments were observed.

**11 is $(1 S 2 R)$-2-aminocycloheptanecarboxylic acid.
Table 5. Diastereoselectivities for cyclopentane $\beta$-amino acids (9 and 10) with different metal ions and reference compounds

\begin{tabular}{lcc}
\hline Metal ion & Reference & $\begin{array}{c}\text { Diastereoselectivity } \\
\left(\mathrm{R}_{\text {cis/trans }}\right)\end{array}$ \\
\hline \hline $\mathrm{Cu}^{2+}$ & L-Pro & $3.27 \pm 0.05$ \\
$\mathrm{Cu}^{2+}$ & D-Pro & $3.53 \pm 0.06$ \\
$\mathrm{Cu}^{2+}$ & L-Phe & $1.72 \pm 0.30$ \\
$\mathrm{Cu}^{2+}$ & $\mathbf{5}$ & $2.93 \pm 0.05$ \\
$\mathrm{Ni}^{2+}$ & L-Pro & $4.81 \pm 0.41$ \\
$\mathrm{Ni}^{2+}$ & D-Pro & $5.32 \pm 0.26$ \\
$\mathrm{Ni}^{2+}$ & $\mathbf{5}$ & $5.95 \pm 0.56$ \\
\hline
\end{tabular}

the only fragments are dimeric $\left[\mathrm{Ni}^{2+}\right.$ (D-Pro)isomer $\mathrm{H}]^{+}$and $\left[\mathrm{Ni}^{2+}(\mathrm{D}-\mathrm{Pro})_{2}-\mathrm{H}\right]^{+}$complex ions. Similar kinds of clear spectra were obtained in most of the cases of dissociation of different trimeric complexes.

The determination of diastereomeric excess by the kinetic method was performed for the norbornane $\beta$-amino acids (1 and 2) and cyclopentane $\beta$-amino acids (9 and 10). First, the calibration plots for both $\beta$-amino acid pairs were determined with nine different mole fractions of isomers, ranging from a pure diastereomer (1:0) to another pure diastereomer $(0: 1)$. For the norbornane $\beta$-amino acids ( $\mathbf{1}$ and 2 ), $\mathrm{Ni}^{2+}$ was used as a metal ion, D-proline was used as a reference compound, and the fragmentation amplitude was $0.25 \mathrm{~V}$. For the cyclopentane $\beta$-amino acids (9 and 10), $\mathrm{Cu}^{2+}$

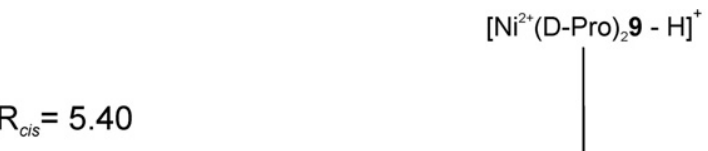

(a) $\mathrm{R}_{\text {cis }}=5.40$

(b)

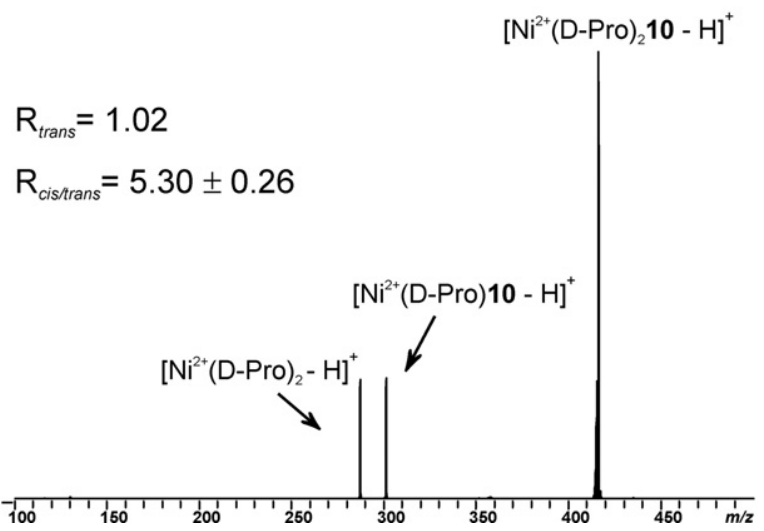

Figure 4. CID spectra of trimeric complexes. (a) cis- and (b) trans-isomers of cyclopentane $\beta$-amino acid (9 and 10). D-Pro was used as a reference compound and $\mathrm{Ni}^{2+}$ as a metal ion. 


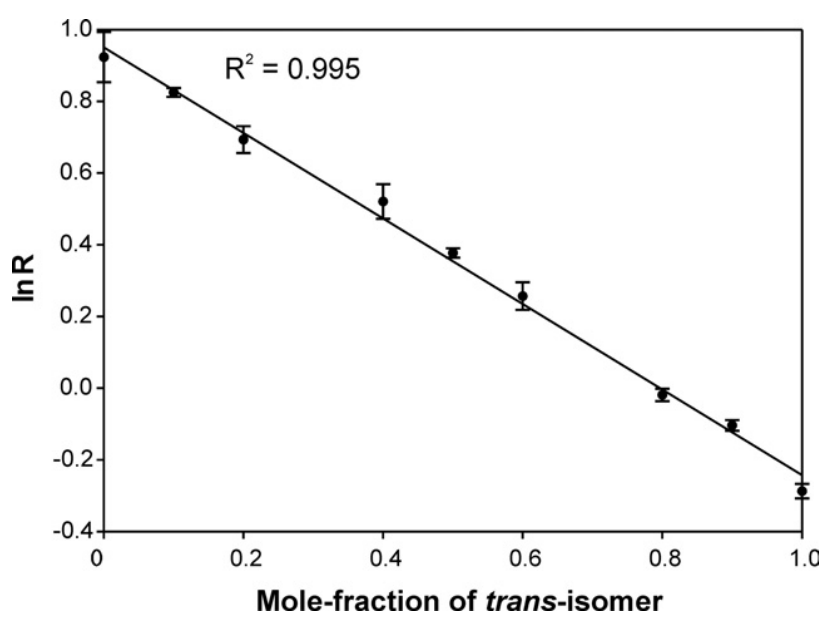

Figure 5. The calibration plot for the determination of diastereomeric excess of trans-cyclopentane $\beta$-amino acid (10).

was used as a metal ion and D-proline as a reference compound. The fragmentation amplitude was $0.25 \mathrm{~V}$.

The calibration plot for cyclopentane $\beta$-amino acids is presented in Figure 5. Measurements were taken three times, and the calibration plot was constructed from the average values (error bars shown). The correlation factor obtained was 0.995 .

Two "unknown" diastereomeric mixtures of cyclopentane $\beta$-amino acids ( 9 and $\mathbf{1 0}$ ) were analyzed under the same conditions as those under which the calibration plot was constructed. The "unknown" mixtures contained mole fractions of 0.25 and 0.95 of a transcyclopentane $\beta$-amino acid. Both measurements were carried out on five separate samples. Using the calibration plot, the average mole fractions of the transcyclopentane $\beta$-amino acid in the two mixtures were calculated to be $0.27 \pm 0.05$ and $0.98 \pm 0.01$.

Similarly, in the case of norbornane $\beta$-amino acids (1 and 2), two "unknown" diastereomeric mixtures with mole fractions of 0.25 and 0.95 of a di-exo norbornane $\beta$-amino acid were analyzed. By using the calibration plot $\left(R^{2}=0.986\right)$, the average mole fractions of the di-exo norbornane $\beta$-amino acid in the two mixtures were calculated to be $0.31 \pm 0.02$ and $0.92 \pm 0.01$. The moderate correlation factor of the calibration plot causes deviations in results.

\section{Conclusions}

Successful differentiation of diastereomeric $\beta$-amino acids (1-10) was performed with the kinetic method with trimeric metal-bound complexes studied via ESIQIT tandem mass spectrometry. The degree of the diastereoselectivity of the $\beta$-amino acids studied was evaluated by altering a reference compound and a metal ion. The notable differentiation of all the diastereomers studied was achieved with the use of trimeric complexes, in which $\mathrm{Cu}^{2+}$ or $\mathrm{Ni}^{2+}$ was used as a metal ion and different $\alpha$ - and $\beta$-amino acids as reference compounds. In addition, successful determination of diastereoisomeric excess was performed for the norbornane $\beta$-amino acids ( $\mathbf{1}$ and $\mathbf{2}$ ) and cyclopentane $\beta$-amino acids ( 9 and 10$)$.

It is worth noting in the case of all the $\beta$-amino acids studied that to achieve a high diastereoselectivity value one does not necessarily need a $\beta$-amino acid as a reference compound. In fact, even better selectivity values were achieved using $\alpha$-amino acids, especially Dand L-Pro, as reference compounds. Proline is quite rigid, with a secondary amino group in the ring skeleton. This rigidity of proline has to have an affect on the high selectivity values obtained. The similarity between the analyte and the reference compound did not improve the selectivity value, except in the case of the norbornene $\beta$-amino acid ( 3 and 4$)$, in which the di-exo norbornane $\beta$-amino acid (2) used as a reference compound yielded high diastereoselectivity.

Altering the metal ion also had some influence on the selectivity values obtained. In general, $\mathrm{Cu}^{2+}$ gave high diastereoselectivity values for all the $\beta$-amino acids studied, but in some cases an additional fragmentation was observed. This additional fragmentation was mainly derived from the loss of $\mathrm{CO}_{2}$ by both dimeric complexes. $\mathrm{Cu}^{2+}$, Lewis acid, binds to the amino acid ligands very tightly, especially via nitrogen, and the fragmentation of $\mathrm{CO}_{2}$ is common [29]. In some cases of norbornene $\beta$-amino acids ( 3 and 4 ) and $\mathrm{Cu}^{2+}$, the loss of $66 \mathrm{Da}$ from a dimeric complex ion was observed, indicating the decomposition reaction of the bicyclic system, known as retro Diels-Alder. When $\mathrm{Ni}^{2+}$ was used as a metal ion, notable differentiation was obtained as well, and additional fragmentation was not observed. Thus, the emphasis lies with the selectivity values obtained with $\mathrm{Ni}^{2+}$ as a metal ion.

This study showed that differentiation of diastereomeric $\beta$-amino acids (1-10) via the kinetic method was more successful than our previous study which used ion/molecule reactions and host-guest complexes [25]. Good selectivities were achieved with ion/molecule reactions but even higher selectivities were now achieved with the trimeric metal-bound complexes. Moreover, the results showed that bicyclic $\beta$-amino acids yielded higher diastereoselectivity values than cyclic $\beta$-amino acids. In addition, more rigid cyclohexene $\beta$-amino acids ( 7 and 8 ) yielded higher selectivity than corresponding cyclohexane $\beta$-amino acids ( 5 and 6). As well, cyclopentane $\beta$-amino acids (9 and 10) showed better selectivity than more flexible cyclohexane $\beta$-amino acids. In general, better diastereoselectivity results correlate with a higher rigidity of the structures studied.

\section{Acknowledgments}

The authors gratefully acknowledge funding provided by the Graduate School of Bioorganic and Medicinal Chemistry, Finland. 


\section{References}

1. McLuckey, S. A.; Cameron, D.; Cooks, R. G. Proton Affinities from Dissociations of Proton-Bound Dimers. J. Am. Chem. Soc. 1981, 103, 1313-1317.

2. McLuckey, S. A.; Patrick, J. S.; Kotiaho, T.; Cooks, R. G. Thermochemical Determinations by the Kinetic Method. Mass Spectrom. Rev. 1994, 13, 287-339.

3. Koskinen, J. T.; Thomas, P. D.; Cooks, R. G. The Kinetic Method of Making Thermochemical Determinations. J. Mass Spectrom. 1999, 34, 85-92.

4. Vékey, K.; Czira, G. Distinction of Amino Acid Enantiomers Based on the Basicity of Their Dimers. Anal. Chem 1997, 69, 1700-1705.

5. Shen, W.; Wong, P. S. H.; Cooks, R. G. Stereoisomeric Distinction by the Kinetic Method: 2,3-Butanediol. Rapid Commun. Mass Spectrom. 1997, 11, $71-74$

6. Tao, W. A.; Zhang, D.; Wang, F.; Thomas, P. D.; Cooks, R. G. Kinetic Resolution of D,L-Amino Acids Based on Gas-Phase Dissociation of Copper(II) Complexes. Anal. Chem. 1999, 71, 4427-4429.

7. Tao, W. A.; Zhang, D.; Nikolaev, E. N.; Cooks, R. G. Copper(II)-Assisted Enantiomeric Analysis of D,L-Amino Acids Using the Kinetic Method: Chiral Recognition and Quantification in the Gas Phase. J. Am. Chem. Soc. 2000, 122, 10598-10609.

8. Zhang, D.; Tao, W. A.; Cooks, R. G. Chiral Resolution of D- and L-Amino Acids by Tandem Mass Spectrometry of Ni(II)-Bound Trimeric Complexes. Int. J. Mass Spectrom. 2001, 204, 159-169.

9. Wu, L.; Tao, W. A.; Cooks, R. G. Ligand and Metal-Ion Effects in Metal-Ion Clusters Used for Chiral Analysis of $\alpha$-Hydroxy Acids by the Kinetic Method. Anal. Bioanal. Chem. 2002, 373, 618-627.

10. Wu, L.; Cooks, R. G. Chiral Analysis Using the Kinetic Method with Optimized Fixed Ligands: Applications to Some Antibiotics. Anal. Chem. 2003, 75, 678-684.

11. Tao, W. A.; Clark, R. L.; Cooks, R. G. Quotient Ratio Method for Quantitative Enantiomeric Determination by Mass Spectrometry. Anal. Chem. 2002, 74, 3783-3789.

12. Tao, W. A.; Gozzo, F. C.; Cooks, R. G. Mass Spectrometric Quantification of Chiral Drugs by the Kinetic Method. Anal. Chem. 2001, 73, 1692-1698.

13. Augusti, D. V.; Carazza, F.; Augusti, R.; Tao, W. A.; Cooks, R. G. Quantitative Chiral Analysis of Sugars by Electrospray Ionization Tandem Mass Spectrometry Using Modified Amino Acids as Chiral Reference Compounds. Anal. Chem. 2002, 74, 3458-3462.

14. Young, B. L.; Cooks, R. G. Improvements in Quantitative Chiral Determinations Using the Mass Spectrometric Kinetic Method. Int. J. Mass Spectrom. 2007, 267, 199-204.

15. Tao, W. A.; Wu, L.; Cooks, R. G. Differentiation and Quantitation of Isomeric Dipeptides by Low-Energy Dissociation of Copper(II)-Bound Complexes. J. Am. Soc. Mass Spectrom. 2001, 12, 490-496.

16. Schug, K. A.; Lemr, K.; Lindner, W. Isomeric Discrimination of ArginineContaining Dipeptides Using Electrospray Ionization-Ion Trap Mass Spectrometry and the Kinetic Method. J. Am. Soc. Mass Spectrom. 2004, $15,840-847$.

17. Schug, K. A.; Lindner, W. Stereoselective Discrimination and Quantification of Arginine and N-Blocked Arginine Enantiomers by Formation and Dissociation of Calcium-Mediated Diastereomeric Trimer Complexes with a Chiral Reference Compound Using Electrospray Ioniza-
tion-Ion Trap Tandem Mass Spectrometry. J. Am. Soc. Mass Spectrom. 2005, 16, 825-834.

18. Wu, L.; Meurer, E. C.; Young, B.; Yang, P.; Eberlin, M. N.; Cooks, R. G. Isomeric Differentiation and Quantification of $\alpha, \beta$-Amino AcidContaining Tripeptides by the Kinetic Method: Alkali Metal-Bound Dimeric Cluster Ions. Int. J. Mass Spectrom. 2004, 231, 103-111.

19. Nagaveni, V.; Prabhakar, S.; Vairamani, M. Differentiation of Underivatized Diastereomeric Hexosamine Monosaccharides and Their Quantification in a Mixture Using the Kinetic Method under Electrospray Ionization Conditions. Anal. Chem. 2004, 76, 3505-3509.

20. Wu, L.; Meurer, E. C.; Cooks, R. G. Chiral Morphing and Enantiomeric Quantification in Mixtures by Mass Spectrometry. Anal. Chem. 2004, 76, 663-671.

21. Fülöp, F. The Chemistry of 2-Aminocycloalkanecarboxylic Acids. Chem. Rev. 2001, 101, 2181-2204

22. Martinek, T. A.; Tóth, G. K.; Fülöp, F. Application of Alicyclic $\beta$-Amino Acids in Peptide Chemistry. Chem. Soc. Rev. 2006, 35, 323-334.

23. Partanen, T.; Stájer, G.; Bernáth, G.; Göndös, G.; Pihlaja, K.; Vainiotalo, P. Mass Spectral Fragmentation Reactions of Some Stereoisomeric Cyclic $\beta$-Amino Acids under Electron and Chemical Ionization. Rapid Commun. Mass Spectrom. 1993, 7, 1121-1125.

24. Hyyryläinen, A. R. M.; Pakarinen, J. M. H.; Stájer, G.; Fülöp, F.; Vainiotalo, P. Diastereochemical Differentiation of $\beta$-Amino Acids Using Host-Guest Complexes Studied by Fourier Transform Ion Cyclotron Resonance Mass Spectrometry. J. Am. Soc. Mass Spectrom. 2007, 18, $1038-1045$.

25. Hyyryläinen, A. R. M.; Pakarinen, J. M. H.; Fülöp, F.; Vainiotalo, P. Differentiation of Diastereomeric Cyclic $\beta$-Amino Acids by Varying the Neutral Reagent in Ion/Molecule Reactions Studied by Electrospray Ionization Fourier Transform Ion Cyclotron Resonance Mass Spectrometry. Rapid Commun. Mass Spectrom. 2008, 22, 1-8.

26. Frisch, M. J.; Trucks, G. W.; Schlegel, H. B.; Scuseria, G. E.; Robb, M. A.; Cheeseman, J. R.; Montgomery, J. A. Jr.; Vreven, T.; Kudin, K. N.; Burant, J. C.; Millam, J. M.; Iyengar, S. S.; Tomasi, J.; Barone, V.; Mennucci, B.; Cossi, M.; Scalmani, G.; Rega, N.; Petersson, G. A.; Nakatsuji, H.; Hada, M.; Ehara, M.; Toyota, K.; Fukuda, R.; Hasegawa, J. Ishida, M. Nakajima, T. Honda, Y. Kitao, O ; Nakai, H. Klene, M Li, X.; Knox, J. E.; Hratchian, H. P.; Cross, J. B.; Bakken, V.; Adamo, C.; Jaramillo, J.; Gomperts, R.; Stratmann, R. E.; Yazyev, O.; Austin, A. J.; Cammi, R.; Pomelli, C.; Ochterski, J. W.; Ayala, P. Y.; Morokuma, K.; Voth, G. A.; Salvador, P.; Dannenberg, J. J.; Zakrzewski, V. G.; Dapprich, S. Daniels, A. D. Strain, M. C.; Farkas, O ; Malick, D. K.; Rabuck A. D.; Raghavachari, K.; Foresman, J. B.; Ortiz, J. V.; Cui, Q.; Baboul, A. G.; Clifford, S.; Cioslowski, J.; Stefanov, B. B.; Liu, G.; Liashenko, A.; Piskorz, P.; Komaromi, I.; Martin, R. L.; Fox, D. J.; Keith, T.; Al-Laham, M. A.; Peng, C. Y.; Nanayakkara, A.; Challacombe, M.; Gill, P. M. W.; Johnson, B.; Chen, W.; Wong, M. W.; Gonzalez, C.; Pople, J. A. Gaussian 03, Rev. C. 02. Gaussian, Inc.: Wallingford CT, 2004.

27. Seymour, J. L.; Malkov, A. V.; Kočovský, P.; Tureček, F. Chiral Recognition in Solution and the Gas Phase. Experimental and Theoretical Studies of Aromatic D- and L-Amino Acid-Cu(II)-Chiragen Complexes. J. Mass Spectrom. 2004, 39, 1044-1052.

28. GaussView 3.0, Gaussian, Inc., CT, USA

29. Tureček, F. Copper-Biomolecule Complexes in the Gas Phase. The Ternary Way. Mass Spectrom. Rev. 2007, 26, 563-582.

30. Alvarez, E. J.; Vartanian, V. H.; Brodbelt, J. S. Metal Complexation Reactions of Quinolone Antibiotics in a Quadrupole Ion Trap. Anal. Chem. 1997, 69, 1147-1155. 